\title{
Hyperglycaemia-induced chemoresistance in breast cancer cells: role of the estrogen receptor
}

\author{
L Zeng $^{1,+}$, H A Zielinska ${ }^{1,+}$, A Arshad', J P Shield ${ }^{1}$, A Bahl ${ }^{2}$, J M P Holly ${ }^{1}$ and C M Perks ${ }^{1}$ \\ ${ }^{1}$ IGFs and Metabolic Endocrinology Group, School of Clinical Sciences, University of Bristol, \\ Learning and Research Building, Southmead Hospital, Bristol BS10 1TD, UK \\ ${ }^{2}$ Department of Clinical Oncology, Bristol Haematology and Oncology Centre, University Hospitals Bristol, \\ Bristol, UK \\ ${ }^{\dagger} \mathrm{L}$ Zeng and $\mathrm{H}$ A Zielinska are co-first authors
}

\author{
Correspondence \\ should be addressed \\ to $\mathrm{C} M$ Perks \\ Email \\ claire.m.perks@bristol.ac.uk
}

\begin{abstract}
Breast cancer patients with diabetes respond less well to chemotherapy; in keeping with this we determined previously that hyperglycaemia-induced chemoresistance in estrogen receptor $(E R \alpha)$ positive breast cancer cells and showed that this was mediated by fatty acid synthase (FASN). More recent evidence suggests that the effect of metabolic syndrome and diabetes is not the same for all subtypes of breast cancer with inferior disease-free survival and worse overall survival only found in women with ER $\alpha$ positive breast cancer and not for other subtypes. Here we examined the impact of hyperglycaemia on ER $\alpha$ negative breast cancer cells and further investigated the mechanism underlying chemoresistance in $E R \alpha$ with a view to identifying strategies to alleviate hyperglycaemia-induced chemoresistance.

We found that hyperglycaemia-induced chemoresistance was only observed in ER $\alpha$ breast cancer cells and was dependent upon the expression of ER $\alpha$ as chemoresistance was negated when the ER $\alpha$ was silenced. Hyperglycaemia-induced an increase in activation and nuclear localisation of the ER $\alpha$ that was downstream of FASN and dependent on the activation of MAPK. We found that fulvestrant successfully negated the hyperglycaemia-induced chemoresistance, whereas tamoxifen had no effect. In summary our data suggests that the ER $\alpha$ may be a predictive marker of poor response to chemotherapy in breast cancer patients with diabetes. It further indicates that anti-estrogens could be an effective adjuvant to chemotherapy in such patients and indicates the importance for the personalised management of breast cancer patients with diabetes highlighting the need for clinical trials of tailored chemotherapy for diabetic patients diagnosed with ER $\alpha$ positive breast cancers.
\end{abstract}

Key Words

- breast cancer
Endocrine-Related Cancer (2016) 23, 125-134

\section{Introduction}

Breast cancer is the most common malignancy in women with a lifetime risk of one in eight. In all Western societies women present with breast cancer are increasingly likely to also suffer from co-morbid conditions such as diabetes and obesity due to the increasingly high prevalence of these conditions in the general population. In a study of over a thousand women treated for breast cancer at MD Anderson Cancer Centre in Houston, 30\% were found to be obese and a further $32 \%$ overweight (Litton et al. 2008). In addition the prevalence of metabolic syndrome in 
patients with breast cancer has been reported to be between 39 and 50\% (Healy et al. 2010, Stebbing et al. 2012).

For all cancers, the co-morbidity of type 2 diabetes has been reported to be associated with poor prognosis and reduced survival: with a mean survival period of 10.4 years for those with diabetes and 14.3 years for those without (Currie et al. 2012). In women with breast cancer, having metabolic syndrome was also associated with more aggressive tumour characteristics (Healy et al. 2010) and being obese confers worse overall survival (Litton et al. 2008).

Evidence also suggests that the effect of metabolic syndrome and diabetes is not the same for all subtypes of breast cancer. In a study of women involved in three large trials, inferior disease-free survival and worse overall survival was only identified in women with estrogen receptor $(\mathrm{ER} \alpha)$ positive breast cancer and not for other subtypes (Sparano et al. 2012). A recent study found that hyperglycaemia was the only feature associated with metabolic syndrome that was associated with disease progression following chemotherapy in a cohort of women with breast cancer ( $73 \%$ of whom had ER $\alpha$ positive tumors; Stebbing et al. 2012).

In an attempt to identify the mechanisms underlying these in vivo clinical observations we previously investigated the impact of raised glucose levels on chemo-sensitivity of ER $\alpha$ positive breast cancer cells. We found that hyperglycaemia-induced chemoresistance in these cells, but not in non-malignant breast epithelial cells, and showed that this was mediated by increased activity of the enzyme fatty acid synthase (FASN), which synthesises fatty acids (with glucose as the main substrate) (Zeng et al. 2010). In keeping with the current clinical data (Stebbing et al. 2012), we found that hyperglycaemia-induced chemoresistance was observed in $\mathrm{ER} \alpha$ positive but not in $\mathrm{ER} \alpha$ negative breast cancer cells. We further determined that a functional $E R \alpha$ was required to mediate the hyperglycaemia-induced chemoresistance and finally that anti-estrogens may be an effective adjuvant to chemotherapy in breast cancer patients with diabetes.

\section{Materials and methods}

\section{Reagents and antibodies}

All chemicals were purchased from Sigma. All siRNAs and the transfection reagent, HiPerFect were purchased from Qiagen.

\section{Cell culture}

The human breast cancer cell lines MCF7, T47D, MDA-MB-231 and Hs578T were purchased from ATCC (Molsheim, France) that authenticates using short tandem repeat DNA profiles and the cells were used for a maximum of ten passages. They were maintained as described before (McIntosh et al. 2010, Zeng et al. 2010).

\section{Dosing protocols}

Cells were seeded in normal $(5 \mathrm{mM})$ glucose-containing growth media for $24 \mathrm{~h}$ and then switched to either high $(25 \mathrm{mM})$ a or normal $(5 \mathrm{mM})$ glucose-containing serum free media for a further $48 \mathrm{~h}$ with or without a MAPK inhibitor, UO126 $(30 \mu \mathrm{m})$ or for $24 \mathrm{~h}$ prior to dosing with chemotherapy drugs doxorubicin $(0-40 \mu \mathrm{M})$, paclitaxel $(0-300 \mu \mathrm{M})$ or C2-ceramide $(0-30 \mu \mathrm{M})$ in the presence or absence of target siRNA to the ER $\alpha$, FASN or non-silencing (ns) siRNA (as described previously (Zeng et al. 2010, Foulstone et al. 2013)), or tamoxifen $(1 \mu \mathrm{M})$ or fulvestrant $(100 \mathrm{nM})$. We used two siRNAs to silence both ER $\alpha$ and FASN: the second siRNA we used in this study for FASN is illustrated in Supplementary Figure 1, see section on supplementary data given at the end of this article.

\section{Cell viability}

This was determined by Trypan blue dye exclusion assay as outlined before (McIntosh et al. 2010, Zeng et al. 2010). We confirmed apoptotic cell death by assessing the cleavage of poly (ADP-ribose) polymerase (PARP) using western immunoblotting as described previously (Thomas et al. 2009).

\section{Cell fractionation assay}

Cytoplasmic and nuclear fractions were separated with NE-PER Nuclear and Cytoplasmic Extraction Kit (Thermo Scientific, Waltham, MA, USA; cat \#78835), following the manufacturers' instructions. Protein content of fractionated proteins and whole cell lysates were assessed using a BCA Protein Assay Reagent Kit (Pierce, Rockford, IL, USA) and then run on either $8 / 12 \%$ SDS-PAGE and transferred to a Hybond-C nitrocellulose membrane (GE Healthcare, Buckinghamshire, UK) as previously described (Zeng et al. 2010). Membranes were probed with p-ER (1:500), p-MAPK (1:1000), MAPK (1:500), tubulin (1:5000), lamin (1:1000), GAPDH

Published by Bioscientifica Ltd 
(1:5000), $\beta$-actin (1:10 000), FASN (1:1000) and ER $\alpha$ (1:750), PARP (1:1000), following the manufacturers' instructions. Tubulin and lamin were used as markers for identifying cytoplasmic and nuclear cell fractions respectively. Secondary antibodies conjugated to peroxidise were used: anti-mouse for p-ER $\alpha$ (1:1500), tubulin (1:5000), lamin (1:2000), GAPDH (1:5000), FASN (1:5000), ER $\alpha$ (1:1500), PARP (1:2000) and $\beta$-actin (1:10 000). Chemiluminescence was detected using the ChemiDoc-IT Imaging (UVP, Bio-Rad) and analysed using Vision Works Analysis Software (UVP, Inc., Upland, CA, USA).

\section{Chromatin immunoprecipitation assay}

Chromatin immunoprecipitation assay (ChIP) was performed using the Imprint Immunoprecipitation Kit (cat \#CHP1) from Sigma-Aldrich. Briefly, after DNA-protein crosslinking with formaldehyde, samples were sonicated and immunoprecipitated with a ChIP grade anti-ER $\alpha$ antibody (Millipore, Watford, Hertfordshire, UK; cat \#17-603). Anti-RNA polymerase II and mouse IgG supplied with the kit were used as positive and negative controls respectively. 5\% input DNA was used for quantification. PCR (HotStarTaq Plus PCR Kit from Qiagen) was performed with purified DNA. The following primers were used for cyclin D1 (CCND1): forward $(-1039)$ AACAAAACCAATTAGGAACCTT, reverse $(-770)$ ATTTCCTTCATCTTGTCCTTCT (as reported in Zheng et al. (2013)) After 38 cycles, PCR products were detected by $2 \%$ agarose gel electrophoresis, stained with Midori Green (Nippon Genetics, Dueren, Germany; \#MG04) and analysed by Bio-Plex Imaging System from Bio-Rad (serial no. 731BR01508).

\section{3-(4,5-dimethylthiazol-2-YI)-2,5-diphenyltetrazolium bromide assay}

The 3-(4,5-dimethylthiazol-2-Yl)-2,5-diphenyltetrazolium bromide (MTT) assay was performed as described previously (Gill et al. 1997, Perks et al. 2003). Briefly, cells were seeded into 96-well plates at 7500 (MCF7) or 22500 (T47D and MDA-MB-231) cells and treated with the chemotherapeutic drugs, doxorubicin, paclitaxel and ceramide for $48 \mathrm{~h}$. Cells were incubated with $7.5 \mathrm{mg} / \mathrm{ml}$ MTT solution for $3 \mathrm{~h}$ at $37^{\circ} \mathrm{C}$. The reaction was stopped by the addition of $50 \mu \mathrm{l}$ stop solution $(0.1 \mathrm{M} \mathrm{HCl}+10 \%$ Triton-100) at room temperature for $20 \mathrm{~min}$. The absorbance at $590 \mathrm{~nm}$ was measured using an ELISA plate reader.

\section{3-(4,5-dimethylthiazol-2-yl)-5-(3-carboxymethoxyphenyl) -2-(4-sulfophenyl)-2H-tetrazolium assay}

Cells were incubated with an 3-(4,5-dimethylthiazol-2-yl)5-(3-carboxymethoxyphenyl)-2-(4-sulfophenyl)-2H-tetrazolium (MTS) ( $2 \mathrm{mg} / \mathrm{ml}$, Promega, cat \#G1118)/phenazine methosulfate (PMS) $(0.92 \mathrm{mg} / \mathrm{ml}$, Sigma P9625) solution at a ratio of $20: 1$ for $3 \mathrm{~h}$ at $37^{\circ} \mathrm{C} .200 \mu \mathrm{l}$ of cell medium was used to measure the absorbance at $490 \mathrm{~nm}$ with an ELISA plate reader. The cells remain viable for further analysis using this assay as opposed to the MTT assay and so we used the MTS assay for experiments in which we also wished to assess cell number and viability.

\section{Statistical analysis}

Data were analysed with SPSS 12.0.1 for Windows using one-way ANOVA followed by least significant difference post-hoc test. A statistically significant difference was considered to be present at $P<0.05$.

\section{Results}

\section{Hyperglycaemia-induced chemoresistance is only observed in ER $\alpha$ positive breast cancer cells}

We demonstrated previously that $\mathrm{ER} \alpha$ positive breast cancer cells, MCF7 and T47D, were resistant to cell death induced by chemotherapeutics (doxorubicin, paclitaxel and ceramide) when exposed to high levels of glucose (Zeng et al. 2010). With MCF7 cells Fig. 1A confirms these previous data and Fig. $1 \mathrm{~B}$ also shows that the MTT assay also indicates the differential effects induced by altered levels of glucose: increasing doses of $\mathrm{C} 2$ reduced metabolic activity more effectively in normal compared to high glucose conditions. Using both the MTT assay and cell counting in this study we found that in contrast to the ER $\alpha$ positive breast cancer cells, ER $\alpha$ negative Hs578T (Fig. 1C and D) and MDAMB-231 (Fig. 1E and F) cells exhibited no chemoresistance following exposure to doxorubicin, paclitaxel or ceramide in high compared to normal glucose conditions. With Hs578T cells ceramide was able to induce cell death at $10 \mu \mathrm{M}$ and not at the lower doses as demonstrated by the induction of PARP cleavage (insert Fig. 1C), this confirms that any differential effects in response to ceramide in relation to the levels of glucose at the lower doses of ceramide as observed in the dose-response (Fig. 1C) were not related to the induction of cell death. We characterised the growth of the cells when exposed to normal and high levels of glucose and found that basal cell growth of ER $\alpha$ positive and negative cells was unaffected over $48 \mathrm{~h}$ by

Published by Bioscientifica Ltd 
A $\quad \operatorname{MCF} 7$ (ER $\alpha$ positive)
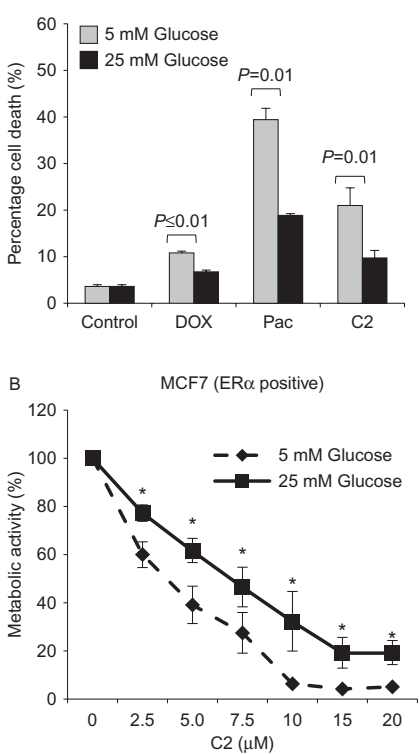

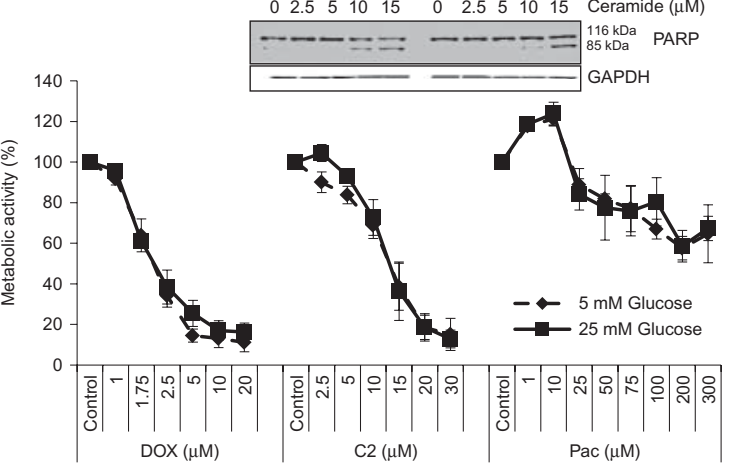

(140

(ER $\alpha$ negative)

$5 \mathrm{mM}$ Glucose $25 \mathrm{mM}$ Glucose

$\begin{array}{llllllll}02.55 & 510 & 15 & 0 & 2.55 & 51015 & \text { Ceramide }(\mu \mathrm{M})\end{array}$
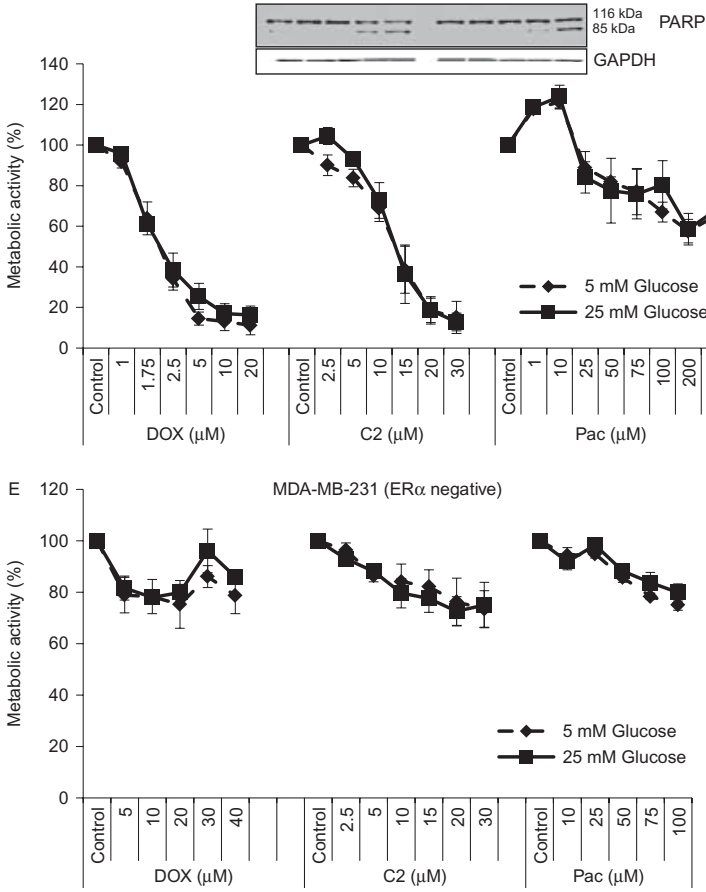
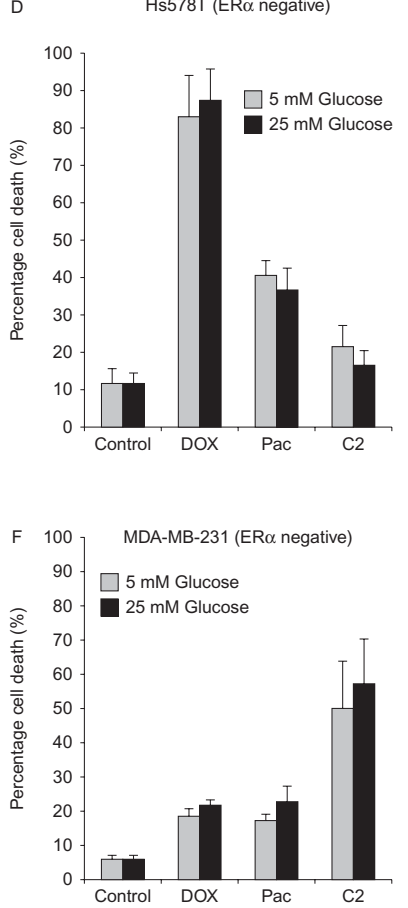

\section{Figure 1}

Hyperglycaemia-induced chemoresistance is only observed in ER $\alpha$ positive breast cancer cells. (A) Using Trypan blue dye exclusion method, the percentage cell death was assessed in the ER $\alpha$ positive MCF7 cells treated with chemotherapeutics (doxorubicin (DOX) $1 \mu \mathrm{M}, P \leq 0.01$; paclitaxel (Pac) $1 \mu \mathrm{M}, P=0.01$ and ceramide (C2) $12 \mu \mathrm{M}, P=0.01$ ) in 5 and $25 \mathrm{mM}$ glucose for $24 \mathrm{~h}$ ( $n=3$ experiments). Changes in metabolic activity of the MCF7 cells in 5 and $25 \mathrm{mM}$ glucose in response to ceramide $(0-20 \mu \mathrm{M})$ was examined using an MTT assay (B) ( $n=3$ experiments, $* P \leq 0.05)$. The metabolic activity of the ER $\alpha$ negative Hs578T cells in 5 and $25 \mathrm{mM}$ glucose in response to DOX

changes in the levels of glucose (Supplementary Figure 2A and $\mathrm{D}$, see section on supplementary data given at the end of this article). Having observed chemoresistance in high glucose in the ER $\alpha$ positive breast cancer cells, we chose MCF7 cells and assessed changes in glucoce uptake and expression of the key glucose transporters 1 (GLUT1) and GLUT12. We found that there was a 1.1-fold increase in glucose uptake in $25 \mathrm{mM}$ glucose that was associated with an increase in expression of GLUT1 $(P<0.05)$ and GLUT12 $(P<0.05)$. Clearly other GLUTs are likely to play a role (Supplementary Figure 3A and C).

\section{Silencing the ER $\alpha$ alleviates chemoresistance in hyperglycaemic conditions in ER $\propto$ positive breast cancer cells}

Having observed that hyperglycaemia only induced chemoresistance in $\mathrm{ER} \alpha$ positive breast cancer cells, we
$(0-20 \mu \mathrm{M}), \mathrm{C} 2(0-30 \mu \mathrm{M})$ and Pac $(0-300 \mu \mathrm{M})$ was examined with MTT assay (C) ( $n=3$ experiments). Insert shows ceramide-induced PARP cleavage ( $85 \mathrm{kDa}$ fragment) by western blotting ( $n=3$ experiments). Percentage of cell death triggered by these drugs in 5 and $25 \mathrm{mM}$ glucose was assessed by Trypan blue dye exclusion assay (D) ( $n=3$ experiments). The change in metabolic activity of another ER $\alpha$ negative cell line, MDA-MB-231 in 5 and $25 \mathrm{mM}$ glucose exposed to the above drugs is shown in (E) and percentage of cell death in (F) ( $n=3$ experiments).

next investigated if the presence of the $\mathrm{ER} \alpha$ was required. With MCF7 cells, we found that in the presence of the ns siRNA, hyperglycaemic conditions reduced the ability of doxorubicin to induce cell death compared to euglycaemic conditions (from 31 to 23\%; $P=0.05$; Fig. 2A) whereas with the $\mathrm{ER} \alpha$ silenced, the hyperglycaemia-induced chemoresistance was negated (Fig. 2A). Similarly with T47D cells (Fig. 2B), in the presence of the ns siRNA, hyperglycaemic conditions reduced the ability of doxorubicin to increase cell death compared to euglycaemic conditions (from 24 to $18 \%$; $P<0.05$; Fig. 2B) whereas with the ER $\alpha$ silenced, the hyperglycaemia-induced chemoresistance was negated (Fig. 2B). With MCF7 and T47D cells we also showed that in the presence of the ns siRNA that high glucose reduced the ability of doxorubicin to decrease metabolic activity (from 0.43- to 0.26-fold and from 0.37- to 0.06-fold; $P=0.05$ and $P<0.05$ respectively; Fig. $2 \mathrm{C}$ and $\mathrm{D}$ ) and that

Published by Bioscientifica Ltd. 


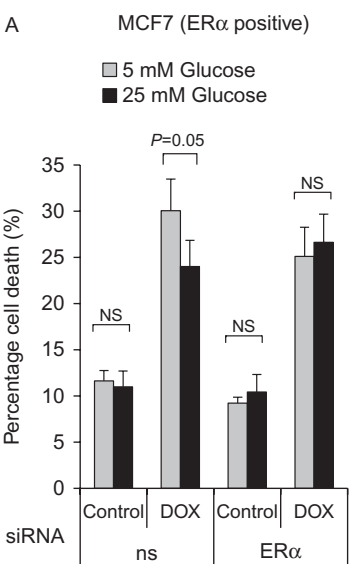

$E$
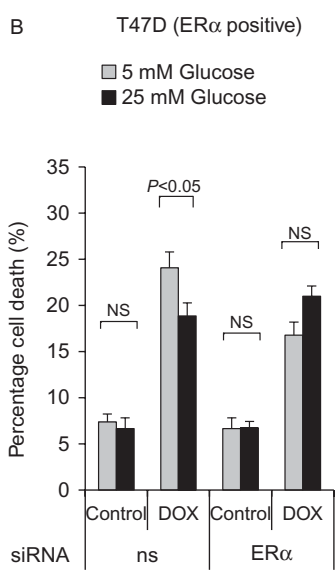

MCF7 (ER $\alpha$ positive)

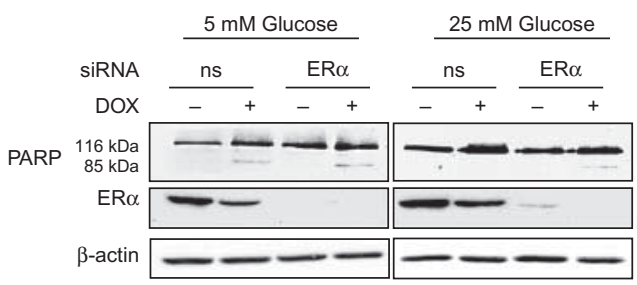

Figure 2

Silencing the ER $\alpha$ alleviates chemoresistance in hyperglycaemic conditions in ER $\alpha$ positive breast cancer cells, compared to the non-silencing (ns) siRNA control. Percentage of cell death induced by doxorubicin (DOX, $1 \mu \mathrm{M}$ in MCF7 and $5 \mu \mathrm{M}$ in T47D cells) was assessed in MCF7 (A) or T47D (B) cells with or without $\mathrm{ER} \alpha$ knocked down with $20 \mathrm{nM}$ siRNA in 5 or $25 \mathrm{mM}$ glucose

this was negated in each cell line when the $\mathrm{ER} \alpha$ was silenced (Fig. 2C and D respectively).

The western blot (Fig. 2E) shows effective silencing of the ER $\alpha$ in both MCF7 and T47D cells in 5 and $25 \mathrm{mM}$ glucose conditions. The blot for PARP also confirms the chemoresistant effect of high glucose by showing a clear reduction in doxorubicin-induced PARP cleavage in the ns hyperglycaemic compared to the ns euglycaemic conditions with both cell lines.

\section{Hyperglycaemia increases phosphorylation and nuclear localization of ER $\alpha$}

Using cellular fractionation followed by western blotting, we examined alterations in the localisation and phosphorylation of ER $\alpha$. With MCF7 cells (Fig. 3A and B), following exposure to high levels of glucose, we observed a shift in the localisation of the ER $\alpha$ with the ratio of ER $\alpha$ in cytoplasmic and nuclear part reduced from 1.9 to 0.8 $(P<0.05)$. As ER $\alpha$ nuclear localisation is concomitant with an increase in $\mathrm{ER} \alpha$ phosphorylation, we assessed changes
C
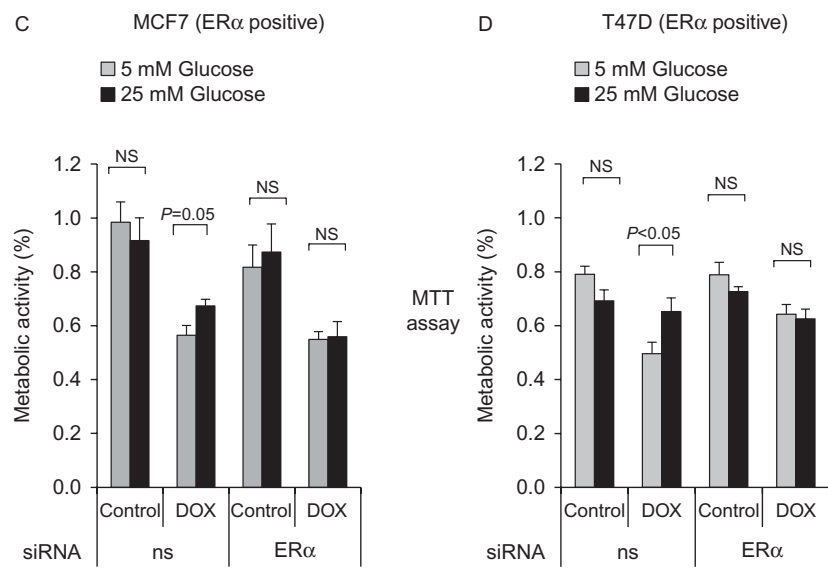

T47D (ER $\alpha$ positive)

$\square 5 \mathrm{mM}$ Glucose

- $25 \mathrm{mM}$ Glucose

$\mathrm{ER} \alpha$

T47D (ER $\alpha$ positive)

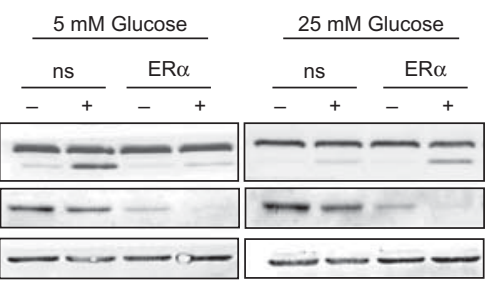

( $n=3$ experiments). Changes of metabolic activity induced by DOX in MCF7 (C) or T47D (D) cells were also measured with or without ER $\alpha$ silencing in 5 or $25 \mathrm{mM}$ glucose ( $n=3$ experiments). Effective ER $\alpha$ knocking down and PARP cleavage was shown in (E). $\beta$-actin probing was used as a loading control ( $n=3$ experiments).

in one of the key ER $\alpha$ phosphorylation sites: ser118. We observed that high levels of glucose increased total levels of $\mathrm{ER} \alpha$ ser118 phosphorylation and that as anticipated there was a 1.6-fold increase in ER $\alpha$ ser118 phosphorylation in the nucleus $(P<0.01)$. Similarly with T47D cells (Fig. 3A and B) we observed a shift in the localisation of the $\mathrm{ER} \alpha$ with the ratio of $\mathrm{ER} \alpha$ in cytoplasmic and nuclear part reduced from 1.4 to $1.1(P<0.05)$ concomitant with a 1.4-fold increase $\mathrm{ER} \alpha$ ser118 phosphorylation in the nucleus $(P<0.05)$.

\section{Hyperglycaemia increases nuclear ER $\alpha$ binding to a target gene, CCND1}

As a further confirmation of the increased nuclear localisation of the $\mathrm{ER} \alpha$, we chose to assess alterations in the association of ER $\alpha$ with one of its known target genes, CCND1. Using ChIP assay we found that high levels of glucose caused a 2.7-fold increase $(P<0.05)$ with MCF7 cells and an 11.7 -fold increase $(P<0.05)$ with T47D cells (Fig. 3C and $\mathrm{D}$ ) in the association of ER $\alpha$ with the CCND1 gene.

Published by Bioscientifica Ltd. 
A
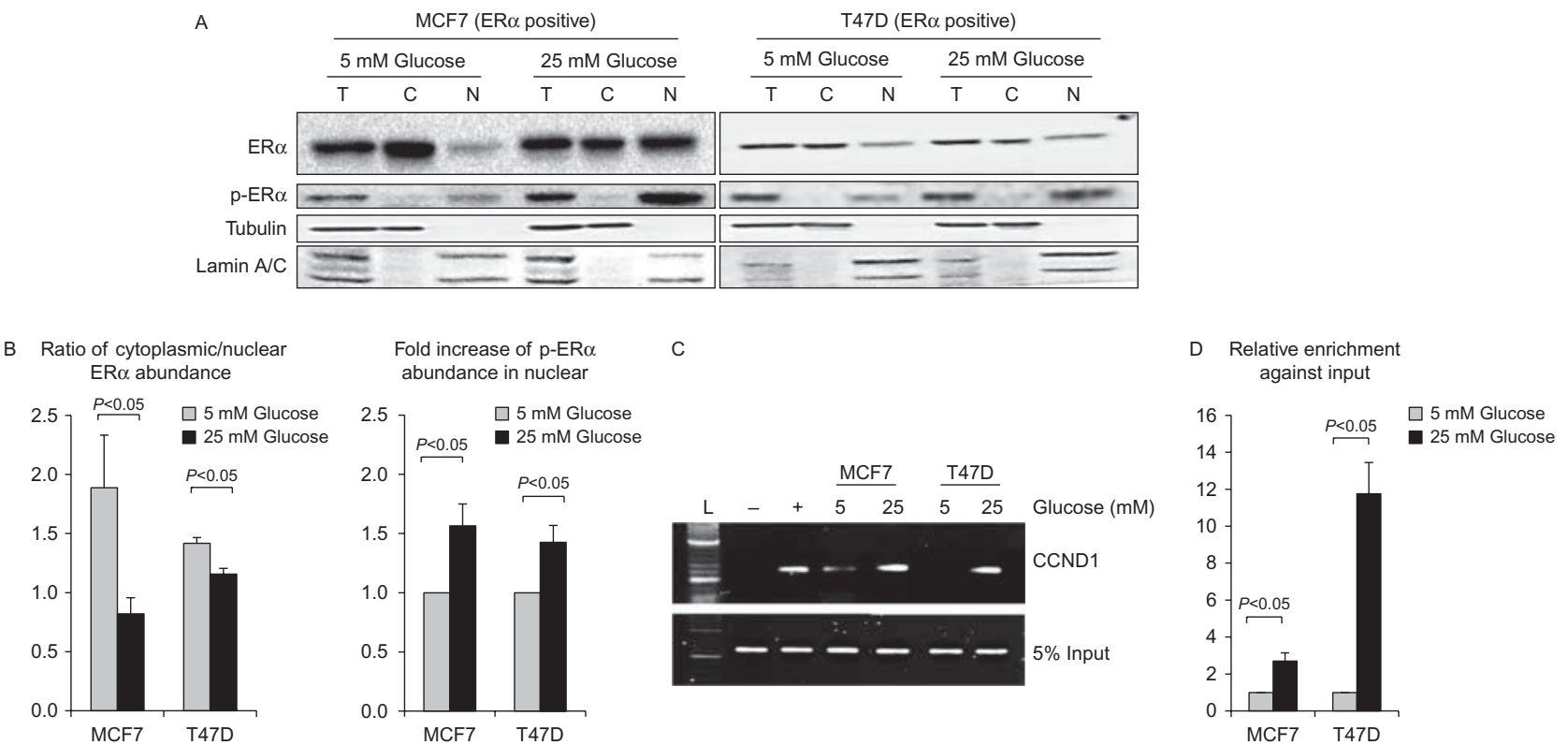

\section{Figure 3}

Hyperglycaemia increases phosphorylation and nuclear localization of ER $\alpha$ and increases nuclear ER $\alpha$ binding to a target gene, cyclin D1 (CCND1). Cell fractionation and western blotting were performed to examine cytoplasmic or nuclear location of ER $\alpha$ and $p-E R \alpha$ (ser118) in MCF7 and T47D cells (A) under 5 or $25 \mathrm{mM}$ glucose condition. Tubulin and lamin A/C blots were used as markers for cytoplasmic and nuclear compartments

\section{The hyperglycamia-induced increase in ER $\alpha$ ser118 phosphorylation is downstream of FASN}

We had shown previously in ER $\alpha$ positive breast cancer cells that hyperglycaemia-induced chemoresistance was dependent upon FASN (Zeng et al. 2010). Having now demonstrated a role for the $\mathrm{ER} \alpha$ in hyperglycaemiainduced chemoresistance, we silenced FASN using siRNA in both MCF7 (Fig. 4A) and T47D (Fig. 4B) cells to determine any impact on the $\mathrm{ER} \alpha$ and levels of $\mathrm{ER} \alpha$ ser118 phosphorylation. We found that silencing FASN reduced levels of the ER $\alpha$ in both normal and high glucose and reduced the ability of hyperglycaemia to activate ER $\alpha$ ser118 phosphorylation (Fig. 4C) suggesting that FASN is acting upstream of the ER $\alpha$.

\section{FASN regulates $p$-ER $\alpha$ (ser118) levels via the MAPK pathway}

Having observed that the effect of hyperglycaemia on the phosphorylation of the ER $\alpha$ was downstream of FASN, we next wished to elucidate the mechanism through which FASN regulated p-ER $\alpha$ ser118 levels. With MCF7 cells, we found that in the presence of the ns FASN siRNA, hyperglycaemic conditions increased p-MAPK respectively ( $n=3$ experiments). The densitometry measurements from the western blot are shown in $(B, P<0.05)$. Chromatin immunoprecipitation assay (ChIP) was used to examine the changes in association of the ER $\alpha$ with one of its target genes, CCND1 (C). $5 \%$ Input was used as a quantification control ( $n=3$ experiments). The relative enrichment of the CCND1 gene bound to $E R \alpha$ was quantified in $(D, P<0.05)$.

levels ( $\times 1.8$-fold increase; $P=0.01$ ) compared to euglycaemic conditions and that this was negated when FASN was silenced (Fig. 5A and B). To determine whether MAPK signalling pathway was required for the hyperglycaemiainduced increase in ER $\alpha$ ser118 phosphorylation, we used U0126, a MAPK inhibitor. As illustrated in Fig. 5C and D, treatment with U0126 completely blocked the ability of hyperglycaemia to activate $\mathrm{ER} \alpha$ ser118 phosphorylation. Taken together, these results indicate that FASN regulates $\mathrm{p}-\mathrm{ER} \alpha$ (ser118) levels via activation of MAPK.

\section{Fulvestrant blocks but tamoxifen has no effect on hyperglycaemia-induced chemoresistance}

Having shown that silencing the ER $\alpha$ using siRNA negated chemoresistance induced by high glucose, we then assessed the effects of blocking the ER in a more clinically relevant manner by using two anti-estrogens, fulvestrant (selective ER down regulator) and tamoxifen (selective ER modulator). We first ensured we were using effective doses of each of the drugs.

With Figs 6A, B and 7A, B we show that fulvestrant and tamoxifen (respectively) effectively blocked estrogeninduced ER $\alpha$ ser118 phosphorylationin both MCF7 and

Published by Bioscientifica Ltd. 


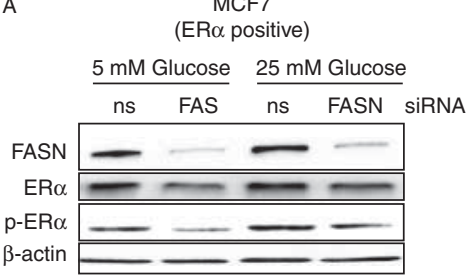

B

T47D
$(\mathrm{ER} \alpha$ positive)

$5 \mathrm{mM}$ Glucose $25 \mathrm{mM}$ Glucose

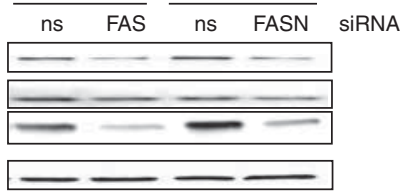

C

Fold changes of $p$-ER $\alpha$ abundance against total $E R \alpha$

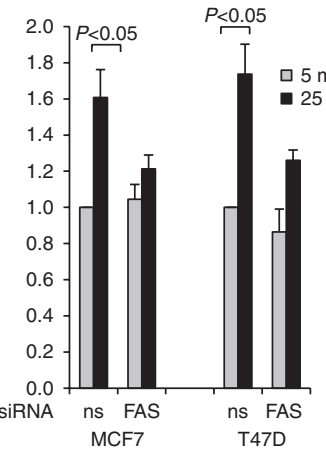

\section{Figure 4}

The hyperglycamia-induced increase in ER $\alpha$ (ser118) phosphorylation is downstream of fatty acid synthase (FASN). Using western blotting, the ER $\alpha$ and p-ER $\alpha$ (ser118) abundance were assessed in MCF7 (A) or T47D (B) cells,

T47D cell lines. We also confirmed in both cell lines that fulvstrant down-regulates the ER $\alpha$ and tamoxifen stabilises it as reported in the literature (Supplementary Figure 3B and C). Having identified effective doses of both drugs we investigated if either fulvestrant or tamoxifen would with or without FASN knocked down with $20 \mathrm{nM}$ siRNA ( $n=3$ experiments). $\beta$-actin was probed as a loading control. Relative fold changes of $p$-ER $\alpha$ (ser118) against total ER $\alpha$ were measured $(C, P<0.05)$.

negate hyperglycaemia-induced chemoresistance as we had observed when the ER was artificially silenced using siRNA. Figure $6 \mathrm{C}$ and D indicate that hyperglycaemiainduced resistance to doxorubicin-induced cell death (18 to $11 \%, P<0.01$ and 13 to $7 \%$ respectively) was
A

MCF-7

(ER $\alpha$ positive)

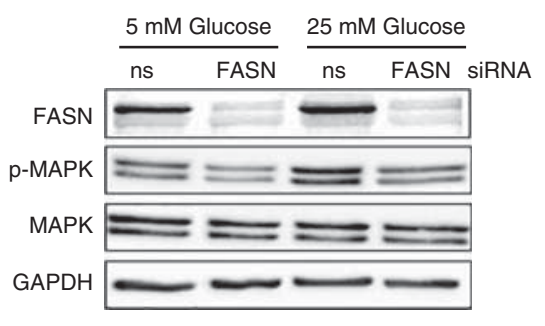

D Fold changes of $\mathrm{p}-\mathrm{MAPK}$ abudance against total MAPK

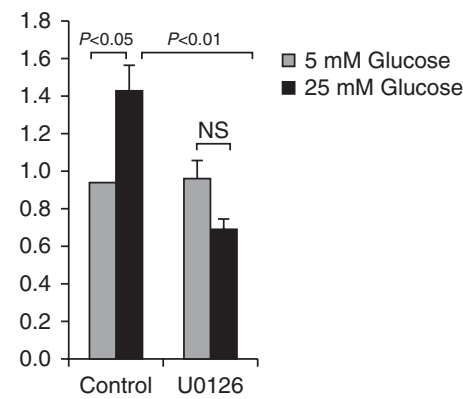

B Fold changes of $\mathrm{p}$-MAPK abudance against total MAPK

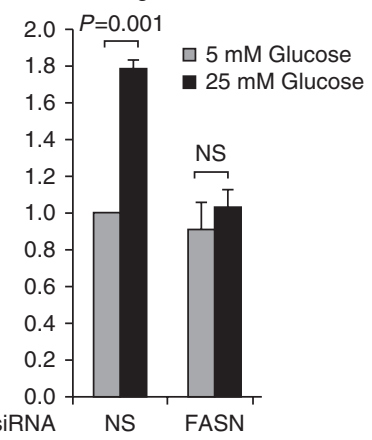

C MCF-7

(ER $\propto$ positive)

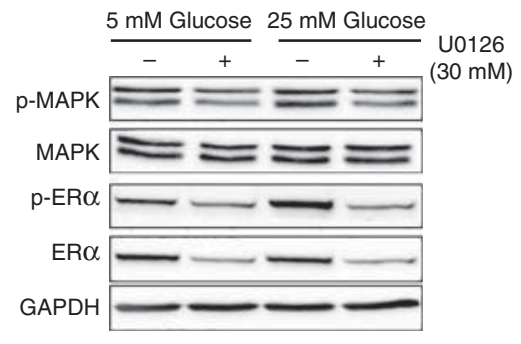

Fold changes of $\mathrm{p}-\mathrm{ER} \alpha$ abudance against total $E R \alpha$

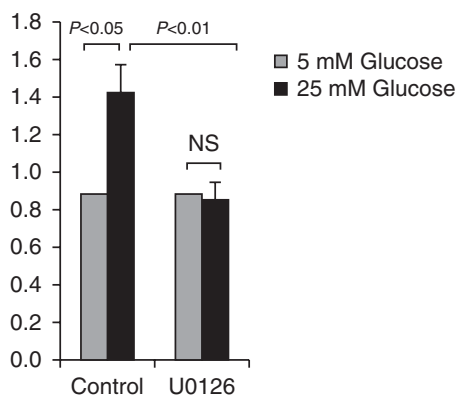

Figure 5

FASN regulates $p$-ER $\alpha$ (ser118) levels via activation of MAPK. Using western blotting, the abundance of MAPK and p-MAPK were assessed in MCF7 cells with or without FASN silenced with $20 \mathrm{nM}$ siRNA in 5 or $25 \mathrm{mM}$ glucose $(n=3$ experiments) (A). Relative fold changes of $p$-MAPK against total MAPK were measured in $(B, P<0.05)$. Effect of MAPK inhibition with $\mathrm{U} 0126$ on $\mathrm{p}$-ER $\alpha$ (ser118) was assessed in MCF7 cells treated with or without U0126 $(30 \mu \mathrm{m})$ in 5 or $25 \mathrm{mM}$ glucose for $48 \mathrm{~h}$ ( $n=3$ experiments) (C). The densitometry measurements from the western blot are shown in $(D, P<0.05)$. 


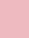
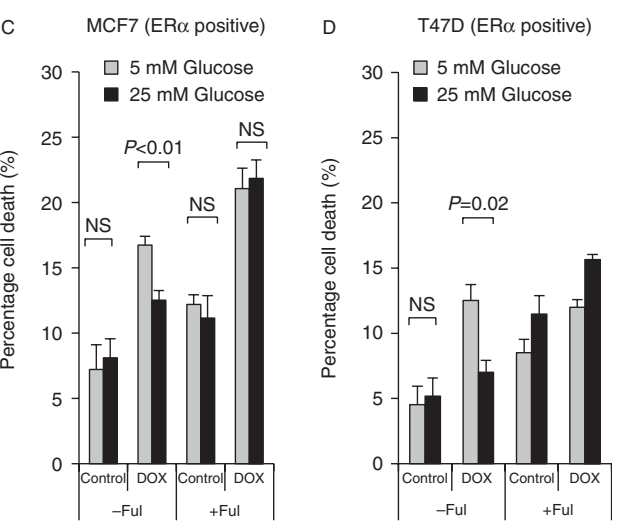

\section{Figure 6}

Fulvestrant blocks hyperglycaemia-induced chemoresistance. MCF7 (A) and T47D (B) cells were treated with the anti-estrogen fulvestrant (Ful) $100 \mathrm{nM}$ $24 \mathrm{~h}$ prior to treatment with $10 \mathrm{nM}$ estrogen for $20 \mathrm{~min}$, in 5 or $25 \mathrm{mM}$ glucose conditions. Western blotting was performed to show protein abundance of $E R \alpha$ and $p$-ER $\alpha$ (ser118). $\beta$-actin was probed as a loading

blocked by fulvestrant in both MCF7 and T47D breast cancer cells. In contrast Fig. 7C (MCF7) and D (T47D) show that tamoxifen was ineffective in negating the hyperglycaemia-induced chemoresistance in either cell line.

\section{Discussion}

The current report has determined that hyperglycaemiainduced chemoresistance only occurs in breast cancer cell lines that possess a functional ER $\alpha$ and has identified that the $\mathrm{ER} \alpha$ is key in mediating this hyperglycaemia-induced chemoresistance. We believe that our novel data may control ( $n=3$ experiments). Percentage of cell death induced by doxorubicin (DOX, $1 \mu \mathrm{M}$ in MCF7 and $5 \mu \mathrm{M}$ in T47D cells) was assessed in MCF7 (C) or T47D (D) cells with or without $24 \mathrm{~h}$ pre-treatment of $100 \mathrm{nM}$ Ful in 5 or $25 \mathrm{mM}$ glucose ( $n=3$ experiments).

explain important clinical observations: in a study of women involved in three large trials, inferior disease-free and overall survival was only found in women with ER positive breast cancer and not for other subtypes (Sparano et al. 2012). In addition, that hyperglycaemia was the only feature associated with metabolic syndrome that was linked with disease progression following chemotherapy in a cohort of women with breast cancer (73\% of whom had ER positive tumors; Stebbing et al. 2012). It has been reported that ERs are important regulators of components of the glycolytic pathway and contribute to the Warburg effect in cancer cells (Cai et al. 2012). Our data indicate
A
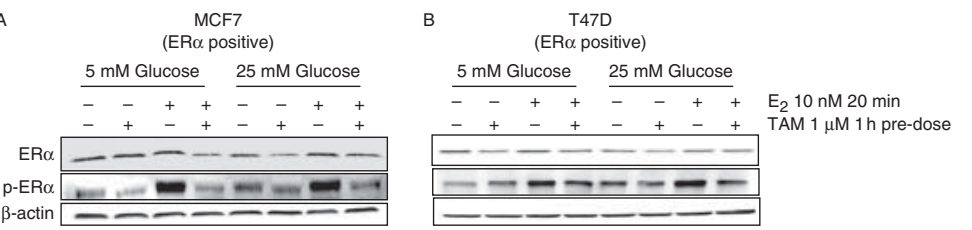
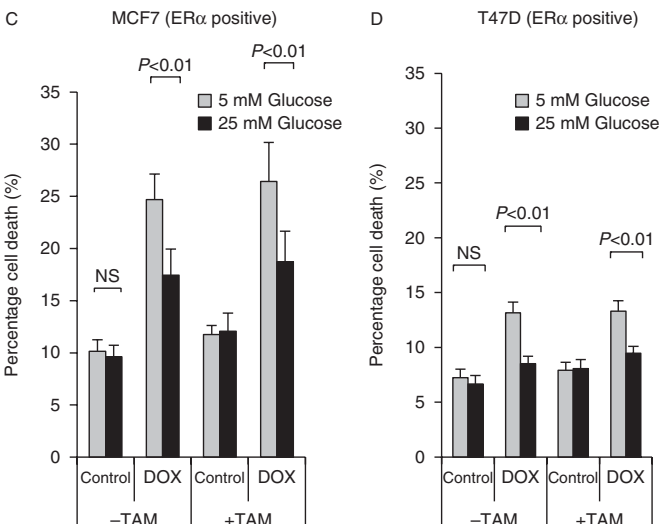

Figure 7

Tamoxifen has no effect on hyperglycaemia-induced chemoresistance. MCF7 (A) and T47D (B) cells were treated with the anti-estrogen tamoxifen (TAM) $1 \mu \mathrm{M} 1 \mathrm{~h}$ prior to treatment with $10 \mathrm{nM}$ estrogen for $20 \mathrm{~min}$, in 5 or $25 \mathrm{mM}$ glucose condition. Western blotting was performed to show protein abundance of $\mathrm{ER} \alpha$ and $\mathrm{p}$-ER $\alpha$ (ser118). $\beta$-actin was probed as a loading control ( $n=3$ experiments). Percentage of cell death induced by doxorubicin (DOX) was assessed in MCF7 (C) or T47D (D) cells with or without $1 \mathrm{~h}$ pre-treatment of $1 \mu \mathrm{M}$ TAM in 5 or $25 \mathrm{mM}$ glucose ( $n=3$ experiments).

Published by Bioscientifica Ltd 
that the ER $\alpha$ is also an important determinant of how metabolic conditions specifically affect breast cancer cells and their response to chemotherapy. We clearly observed that silencing the ER $\alpha$ in ER $\alpha$ positive breast cancer cells negated hyperglycaemia-induced chemoresistance; consistent with these findings we determined that exposing ER $\alpha$ negative breast cancer cells to different levels of glucose did not influence chemo-sensitivity. The $\mathrm{ER} \alpha$ has been linked to chemoresistance previously: Tokuda et al. (2012) showed that silencing the ER $\alpha$ in MCF7 breast cancer cells enhanced sensitivity to paclitaxel. This study was only performed under hyperglycaemic conditions and in that context their results were consistent with our findings.

As the $\mathrm{ER} \alpha$ can be located at numerous sites within the cell we assessed if exposure to high glucose impacted on the localisation of the ER $\alpha$. We found that hyperglycaemia increased the relative amounts of ER $\alpha$ in the nucleus compared to the cytoplasm. The ER $\alpha$ needs to be phosphorylated to translocate to the nucleus: in keeping with the ER $\alpha$ localisation data we observed a significant increase in phosphorylation of ER $\alpha$ at ser118. To corroborate these findings we assessed the level of ER $\alpha$ binding to one of its known target genes, CCND1 when exposed to different levels of glucose: as anticipated based on the localisation and phosphorylation data, we found an increase in association of the ER $\alpha$ with the CCND1 gene when ER $\alpha$ positive breast cancer cells were exposed to high levels of glucose. Ross-Innes et al. (2012) assessed the dynamics of ER $\alpha$ binding to DNA in clinical breast cancer samples and found that differential ER $\alpha$ binding was associated with clinical outcome in breast cancer: ER $\alpha$ bound to different sites and with different affinities depending on the stage. In light of these novel findings our data may suggest that breast cancer patients with altered metabolism may have tumour cells with altered ER $\alpha /$ DNA binding patterns that may contribute to chemoresistance.

We showed previously that hyperglycaemia-induced chemoresistance was dependent upon FASN (Zeng et al. 2010). Associations between the ER $\alpha$ and FASN have been identified in breast cancer cells previously (Lupu \& Menendez 2006). We delineated that our new data, showing the important role of the $\mathrm{ER} \alpha$, was related to our previously defined signalling pathway. Our data suggests that the effect of hyperglycaemia on the phosphorylation of the $\mathrm{ER} \alpha$ is downstream of FASN as silencing FASN reduced activation of the ER $\alpha$ : in addition that the increased phosphorylation of the $E R \alpha$ was mediated by MAPK activation downstream of FASN.
We then blocked the ER in a more clinically relevant manner using two anti-estrogens, fulvestrant and tamoxifen to assess their effectiveness in alleviating the resistance induced by hyperglycaemic conditions. We found that fulvestrant successfully negated the hyperglycaemia-induced chemoresistance, whereas tamoxifen had no effect. We believe this relates to how these two drugs act: fulvestrant degrades the $\mathrm{ER} \alpha$ whereas tamoxifen stabilises the protein. The mechanism by which fulvestrant acts would be most comparable to our experiments where we artificially silenced the ER $\alpha$ with siRNA.

In summary our data provides a mechanism to support the clinical studies indicating that women with $\mathrm{ER} \alpha$ positive breast cancer who also have diabetes respond less well to chemotherapy: it suggests that the ER $\alpha$ may be a predictive marker of poor response to chemotherapy in breast cancer patients with diabetes. It further indicates that certain classes of anti-estrogen therapy may prove effective adjuvants to chemotherapy in such patients but the specific type of anti-estrogen needs to be considered carefully. Our data indicates the potential importance and benefit of personalised medical therapy in the management of breast cancer, highlighting the need for clinical trials of tailored chemotherapy for diabetic patients diagnosed with $\mathrm{ER} \alpha$ positive breast cancers.

\section{Supplementary data}

This is linked to the online version of the paper at http://dx.doi.org/10.1530/ ERC-15-0507.

\section{Declaration of interest}

The authors declare that there is no conflict of interest that could be perceived as prejudicing the impartiality of the research reported.

\section{Funding}

This work was supported by The European Foundation for the Study of Diabetes (EFSD).

\section{Author contribution statement}

L Zeng, H A Zielinska and A Arshad performed the research experiments. C M Perks wrote the manuscript, contributed to the design, obtained the funding and supervised the study. J M P Holly contributed to the design, supervision and to the writing of the paper. A Bahl and J P Shield also contributed to writing the paper and provided invaluable advice regarding the potential clinical applications of the work.

Acknowledgements

We thank Lindsay Durant for contributing to this work.

Published by Bioscientifica Ltd 


\section{References}

Cai Q, Lin T, Kamarajugadda S \& Lu J 2012 Regulation of glycolysis and the Warburg effect by estrogen-related receptors. Oncogene 32 2079-2086. (doi:10.1038/onc.2012.221)

Currie CJ, Poole CD, Jenkins-Jones S, Gale EA, Johnson JA \& Morgan CL 2012 Mortality after incident cancer in people with and without type 2 diabetes: impact of metformin on survival. Diabetes Care 35 299-304. (doi:10.2337/dc11-1313)

Foulstone EJ, Zeng L, Perks CM \& Holly JM 2013 Insulin-like growth factor binding protein 2 (IGFBP-2) promotes growth and survival of breast epithelial cells: novel regulation of the estrogen receptor. Endocrinology 154 1780-1793. (doi:10.1210/en.2012-1970)

Gill ZP, Perks CM, Newcomb PV \& Holly JM 1997 Insulin-like growth factor-binding protein (IGFBP-3) predisposes breast cancer cells to programmed cell death in a non-IGF-dependent manner. Journal of Biological Chemistry 272 25602-25607. (doi:10.1074/jbc.272.41.25602)

Healy LA, Ryan AM, Carroll P, Ennis D, Crowley V, Boyle T, Kennedy MJ, Connolly E \& Reynolds JV 2010 Metabolic syndrome, central obesity and insulin resistance are associated with adverse pathological features in postmenopausal breast cancer. Clinical Oncology 22 281-288. (doi:10.1016/j.clon.2010.02.001)

Litton JK, Gonzalez-Angulo AM, Warneke CL, Buzdar AU, Kau SW, Bondy M, Mahabir S, Hortobagyi GN \& Brewster AM 2008 Relationship between obesity and pathologic response to neoadjuvant chemotherapy among women with operable breast cancer. Journal of Clinical Oncology 26 4072-4077. (doi:10.1200/JCO.2007.14.4527)

Lupu R \& Menendez JA 2006 Targeting fatty acid synthase in breast and endometrial cancer: an alternative to selective estrogen receptor modulators? Endocrinology 147 4056-4066. (doi:10.1210/en.20060486)

McIntosh J, Dennison G, Holly JM, Jarrett C, Frankow A, Foulstone EJ, Winters ZE \& Perks CM 2010 IGFBP-3 can either inhibit or enhance EGF-mediated growth of breast epithelial cells dependent upon the presence of fibronectin. Journal of Biological Chemistry $\mathbf{2 8 5}$ 38788-38800. (doi:10.1074/jbc.M110.177311)

Perks CM, Newcomb PV, Grohmann M, Wright RJ, Mason HD \& Holly JM 2003 Prolactin acts as a potent survival factor against C2-ceramideinduced apoptosis in human granulosa cells. Human Reproduction 18 2672-2677. (doi:10.1093/humrep/deg496)

Ross-Innes CS, Stark R, Teschendorff AE, Holmes KA, Ali HR, Dunning MJ, Brown GD, Gojis O, Ellis IO, Green AR et al. 2012 Differential oestrogen receptor binding is associated with clinical outcome in breast cancer. Nature 481 389-393. (doi:10.1038/nature10730)

Sparano JA, Wang M, Zhao F, Stearns V, Martino S, Ligibel JA, Perez EA, Saphner T, Wolff AC, Sledge GW Jr et al. 2012 Obesity at diagnosis is associated with inferior outcomes in hormone receptor-positive operable breast cancer. Cancer 118 5937-5946. (doi:10.1002/cncr.27527)

Stebbing J, Sharma A, North B, Athersuch TJ, Zebrowski A, Pchejetski D, Coombes RC, Nicholson JK \& Keun HC 2012 A metabolic phenotyping approach to understanding relationships between metabolic syndrome and breast tumour responses to chemotherapy. Annals of Oncology 23 860-866. (doi:10.1093/annonc/mdr347)

Thomas F, Patel S, Holly JM, Persad R, Bahl A \& Perks CM 2009 Dihydrotestosterone sensitises LNCaP cells to death induced by epigallocatechin-3-gallate (EGCG) or an IGF-I receptor inhibitor. Prostate 69 219-224. (doi:10.1002/pros.20873)

Tokuda E, Seino Y, Arakawa A, Saito M, Kasumi F, Hayashi S \& Yamaguchi Y 2012 Estrogen receptor- $\alpha$ directly regulates sensitivity to paclitaxel in neoadjuvant chemotherapy for breast cancer. Breast Cancer Research and Treatment 133 427-436. (doi:10.1007/s10549-011-1758-x)

Zeng L, Biernacka KM, Holly JM, Jarrett C, Morrison AA, Morgan A, Winters ZE, Foulstone EJ, Shield JP \& Perks CM 2010 Hyperglycaemia confers resistance to chemotherapy on breast cancer cells: the role of fatty acid synthase. Endocrine-Related Cancer 17 539-551. (doi:10.1677/ ERC-09-0221)

Zheng L, Qi T, Yang D, Qi M, Li D, Xiang X, Huang K \& Tong Q 2013 MicroRNA-9 suppresses the proliferation, invasion and metastasis of gastric cancer cells through targeting cyclin D1 and Ets1. PLoS ONE 8 e55719. (doi:10.1371/journal.pone.0055719)

Received in final form 3 November 2015

Accepted 1 December 2015

Made available online as an Accepted Preprint

7 December 2015
(C) 2016 Society for Endocrinology Printed in Great Britain 